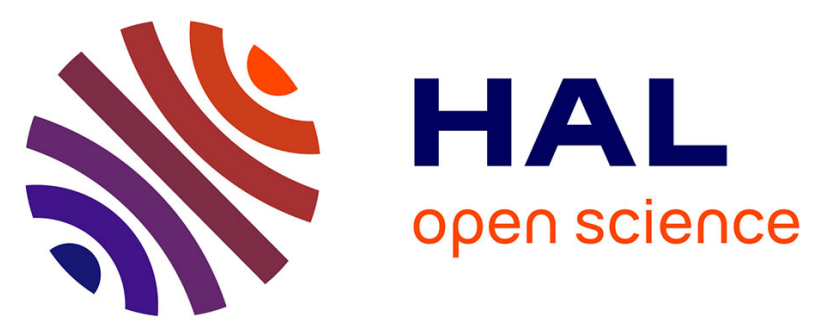

\title{
Mechanistic Investigation of $\epsilon$-Thiono-Caprolactone Radical Polymerization: An Interesting Tool to Insert Weak Bonds into Poly(vinyl esters)
}

Christopher M Plummer, Noémie Gil, Pierre-Emmanuel Dufils, D. James Wilson, Catherine Lefay, Didier Gigmes, Yohann Guillaneuf

\section{To cite this version:}

Christopher M Plummer, Noémie Gil, Pierre-Emmanuel Dufils, D. James Wilson, Catherine Lefay, et al.. Mechanistic Investigation of $\epsilon$-Thiono-Caprolactone Radical Polymerization: An Interesting Tool to Insert Weak Bonds into Poly(vinyl esters). ACS Applied Polymer Materials, 2021, 3 (6), pp.3264-3271. 10.1021/acsapm.1c00569 . hal-03357740

\author{
HAL Id: hal-03357740 \\ https://hal.science/hal-03357740
}

Submitted on 29 Sep 2021

HAL is a multi-disciplinary open access archive for the deposit and dissemination of scientific research documents, whether they are published or not. The documents may come from teaching and research institutions in France or abroad, or from public or private research centers.
L'archive ouverte pluridisciplinaire HAL, est destinée au dépôt et à la diffusion de documents scientifiques de niveau recherche, publiés ou non, émanant des établissements d'enseignement et de recherche français ou étrangers, des laboratoires publics ou privés. 


\title{
Mechanistic Investigation of the $\varepsilon$-Thiono- Caprolactone Radical Polymerization: An Interest- ing Tool to Insert Weak Bonds into Poly(vinyl es- ters)
}

\author{
Christopher M. Plummer, ${ }^{\mathrm{a}}$ Noémie Gil, ${ }^{\mathrm{a}}$ Pierre-Emmanuel Dufils, ${ }^{\mathrm{b}}$ James Wilson, ${ }^{\mathrm{b}}$ Catherine Lefay, ${ }^{\mathrm{a}}$ \\ Didier Gigmes, ${ }^{a}$ Yohann Guillaneuf ${ }^{\mathrm{a}, *}$ \\ ${ }^{a}$ Aix-Marseille Univ., CNRS, Institut de Chimie Radicalaire, UMR 7273, F-13397 Marseille, France \\ Email: yohann.guillaneuf@univ-amu.fr \\ ${ }^{\text {b }}$ Solvay Novecare, Research and Innovation Centre - Paris, 93306 Aubervilliers, France
}

\begin{abstract}
The incorporation of heteroatoms into the backbone of commodity polymers prepared by radical polymerization is an elegant way to confer (bio)degradability to such materials. This could be achieved via the radical ring-opening polymerization of cyclic monomers. Thionolactones were recently identified as promising comonomers for rROP but only reacting with activated monomers such as acrylate and acrylamide derivatives. Herein, we describe two thionolactone monomers, oxepane-2-thione i.e. $\varepsilon$ thiono-caprolactone (thCL) and 7-butyloxepane-2-thione, i.e $\varepsilon$-thiono-decalactone (thDL) capable of performing radical ringopening polymerization with less activated monomers such as vinyl acetate (VAc) to produce readily degradable copolymers via the insertion of thioester containing repeating units. A thorough mechanistic investigation was performed to understand the reactivity of the two cyclic monomers. We identified the initiation as the main parameter to perform the polymerization of such thionolactone monomers. In a specific case the poly( $\varepsilon$-thCL) homopolymer was successfully obtained. Concerning the copolymerization with vinyl acetate, a variety of polymerizations with differing feed ratios were performed, and the degradability of the copolymers via aminolysis examined by SEC. To demonstrate the usefulness of thionolactones a variety of block copolymers containing thioester linkages involving $N, N$-dimethylacrylamide and VAc were also prepared and degraded.
\end{abstract}

KEYWORDS: thionolactone, radical ring-opening polymerization, degradable (co)polymers, polythioester, poly(vinyl acetate)

\section{INTRODUCTION}

The versatility and durability of plastics, coupled with their low cost of production, has resulted in an annual worldwide production exceeding 335 million tonnes. While some polymer waste is incinerated for energy production, most is either discarded into landfill or directly into the natural environment. ${ }^{1,2}$ Microplastic particles are currently also becoming pervasive throughout the natural environment, with unknown consequences. $^{3}$ There is therefore a necessity for polymeric materials intended to undergo programmed (bio)degradation, thereby returning the polymer chains to oligomers that can be readily consumed by microbial action.

An emerging technique to produce (bio)degradable polymers from vinyl-based materials is the copolymerization of specifically designed monomers with conventional monomer feedstock. This can be readily accomplished by the polymerization technology known as radical ring-opening polymerization (rROP) which allows the ability to install ester-linkages into the backbone of polymers produced by free-radical polymerization. $^{4-6}$ Such ester-linkages impart (bio)degradability, with only a minor quantity being required to be introduced into the polymer backbone for its complete degradation, pending homogeneous incorporation. In detail, the technique of rROP involves the (co)polymerization of cyclic monomers bearing either a vinyl or exomethylene group (or an analogous sp2 system) which can undergo polymerization by a free-radical pathway via a ring-opening mechanism. Radical ring-opening polymerization combines the advantages of both ring-opening polymerization (ROP) and radical polymerization in one polymerization system i.e., the production of polymers having heteroatom and/or functional groups within the backbone chain, combined with the robustness and mild conditions of a free-radical polymerization process. ${ }^{4-6}$

A complication encountered with (bio)degradable copolymers produced via rROP is that the incorporated monomers are required to be situated in a homogenous distribution to impart substantial hydrolysable functionality into the parent polymer. ${ }^{7}$ The control of such phenomena relates to the reactivity ratios of the two monomer compounds, as well as variables such as temperature, monomer concentration, and polymerization time, etc. The most well-studied and understood rROP monomer family can be considered the cyclic ketene acetals (CKAs) (Figure 1a, example 2-methylene-1,3-dioxepane, MDO) which produce polyesters. Various CKA molecules with diverse ringsizes and substituents have been synthesized and evaluated for their rROP ability. ${ }^{4,5}$ Even if the use of CKAs has led to the preparation of a wide variety of (bio)degradable materials, 
such monomer families are sensitive to protic sources and also have a rather low reactivity compared to many vinyl-based monomers. ${ }^{8}$ Thus, there remains room for innovation to prepare other rROP monomers.

a)
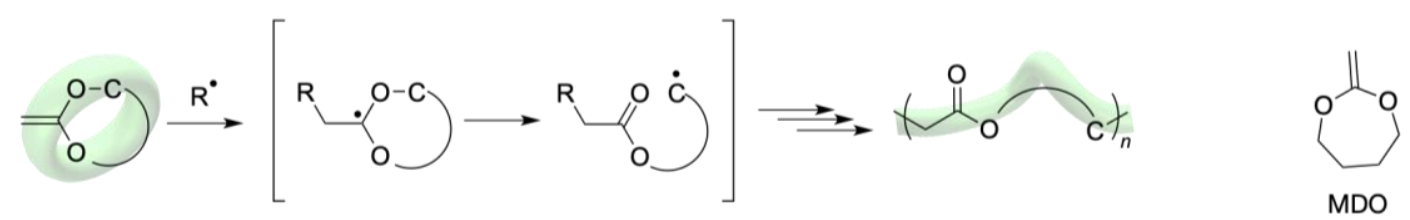

b)
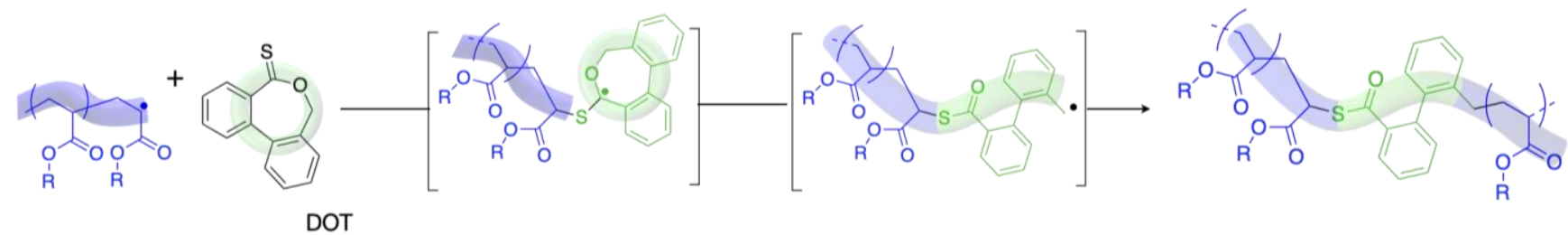

Figure 1. a) Preparation of polyesters via the radical ring-opening polymerization of cyclic ketene acetals. b) Radical ring-opening copolymerization of a thionolactone to introduce thioester linkages into the polymer backbone.

Other structures such as cyclic allyl sulfide or allyl sulfone have been designed but require long synthetic procedures. ${ }^{9,10} \mathrm{~A}$ relatively new class of rROP monomers are the thionolactones, which were simultaneously discovered by Roth $^{11}$ and Gutekunst ${ }^{12}$ (Figure 1b). In particular, Roth ${ }^{11}$ showed that among the various thionolactone compounds, only dibenzo[c,e $]$ oxepine-5(7H)-thione (Figure $1 \mathrm{~b}$, DOT) is reported to solely undergo ring-opening copolymerization, leading to polymers with thioester functionality within the polymer backbone. Its copolymerization with acrylonitrile, acrylates, acrylamides and maleimides derivatives were reported to be efficient whereas copolymerizations with styrene, methacrylate derivatives and vinyl acetate were not successful. ${ }^{11,}{ }^{13}$ The homopolymerization was also not efficient. ${ }^{13}$ Since only a single thionolactone monomer (DOT, 2) has been reported to be able to undergo rROP, we sought to evaluate other potential analogues. The addition-fragmentation ability of the $\mathrm{C}=\mathrm{S}$ bond has been widely investigated during the development of the RAFT process. ${ }^{14,}{ }^{15}$ In particular, it was demonstrated that dithiobenzoate derivatives were efficient for stabilized vinyl monomers such as acrylate derivatives but unreactive with low-stabilized monomers. ${ }^{16,17}$ Changing aryl to alkyl groups is known to decrease the transfer constant of the RAFT agent and thus allow for the use of less activated monomers. ${ }^{16}$ By analogy, we could expect that preparing a thionolactone without the presence of the phenyl group could lead to an efficient rROP monomer that is compatible with less activated monomers, such as vinyl ester derivatives. Indeed, previous research into the CKA monomers has revealed that 7membered rings most readily undergo $\mathrm{rROP}$ and therefore the removal the substituted benzene rings of the DOT structure to give the 7-membered core was envisioned. During the writing of this manuscript, Destarac and coworkers ${ }^{18}$ presented the $\varepsilon$ thionocaprolactone as a new thionolactone that could be used as a comonomer with vinyl acetate, but that could not homopolymerize.

\section{RESULTS AND DISCUSSION}

Radical reactivity. To access the targeted molecules, we applied a procedure for $\varepsilon$-caprolactone thiation involving phosphorus sulfide $\left(\mathrm{P}_{4} \mathrm{~S}_{10}\right)$ and hexamethyldisiloxane (HMDSO). ${ }^{19}$ The target thiono-caprolactone (thCL) and thiono-decalactone (thDL) were readily isolated as yellow oils in $56-64 \%$ yield after flash chromatography (Scheme 1). It was found that the $\varepsilon$-thionocaprolactone (thCL) was unstable in the presence of water, particularly in the presence of alcohols which appeared to catalyse the degradation. Degradation reactions include an oxidation to $\varepsilon$-caprolactone, as well as hydrolysis to give the ring-opened product. The compound is however stable stored neat in a refrigerator. Attempts to initiate the homopolymerization of thCL using AIBN, BPO and ammonium persulfate under various conditions all failed, as also reported. ${ }^{18}$

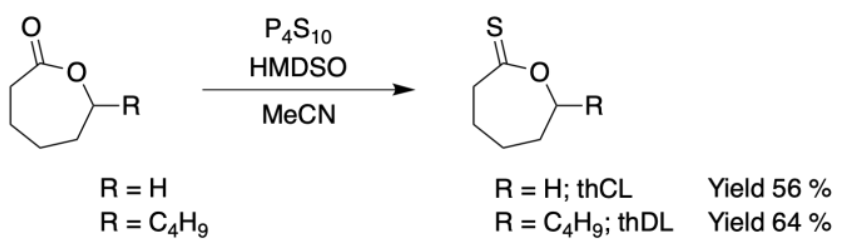

Scheme 1. Preparation of the seven-membered ring alkyl thionolactones.

One hypothesis to explain such results is related to the initiation of the polymerization. Indeed, the initiating radical should first add efficiently to the $\mathrm{C}=\mathrm{S}$ bond. Secondly the intermediate radical should fragmentate to release the thioester bond and a new primary (for thCL) alkyl radical, without reversal to give back the thCL monomer and the initiating radical. In this case, the produced radical is a non-stabilized radical and thus the reversal could be the main reaction event, inhibiting the polymerization. To test this hypothesis, we thought to copolymerize the thCL monomer with the CKA monomer 2methylene-1,3-dioxepane (MDO). In the case of CKA, it is known that AIBN-derived radicals add efficiently onto the exomethylene double bond and thus irreversible $\beta$-fragmentation occurs leading to a primary non-stabilized radical. ${ }^{20}$ After addition to this non-stabilized radical, the ringopening of the thCL will be favored. Interestingly, such a copolymerization system initiated by AIBN readily provided copolymers poly(MDO-co-thCL) and even the homopolymer of thCL, depending on the feed ratio (Scheme 2) (See Figure S5 and S6 for NMR spectra). This result showed that contrary 
to the hypothesis of Destarac, ${ }^{18}$ the difficulty in homopolymerizing thCL is not due to a slow propagation profile, but to the initiation system. Indeed, common initiating systems such as AIBN lead to stabilized radicals that add very efficiently to the $\mathrm{C}=\mathrm{S}$ bond but could also undergo reversible fragmentation to release the radical and the starting thionolactone. When MDO is present in the medium in a sufficient quantity, the irreversible addition of initiating radicals onto MDO occurs allowing for the production of nonstabilized alkyl radicals that initiate the efficient homopolymerization of the thCL, or the copolymerization, depending on the monomer ratio. When the amount of MDO is too low (MDO only as a co-initiator at $3 \mathrm{~mol} \%$ ) no polymer was obtained, showing that most of the AIBN-type initiating radicals are sequestered by the thCL. When the amount of MDO is moderate, only the polythioester poly(thiocaprolactone) or poly(thCL) is obtained, demonstrating that the rate of thCL polymerization is higher than that of MDO. Only when a high ratio of MDO is used that a copolymer is obtained (Scheme 2). We thus attempted to use other systems to generate non-stabilized alkyl radicals to initiate the polymerization: via iodine-transfer polymerization (ITP) using perfluorinated 1 -iodohexane as the alkyl iodide, ${ }^{21}$ and using Fenton chemistry involving $\mathrm{FeSO}_{4}$ and $\mathrm{H}_{2} \mathrm{O}_{2}$ to generate methyl radicals. ${ }^{22}$ These system did not allow access to the polythioester, demonstrating that a specific initiation process has still to be determined.

a)

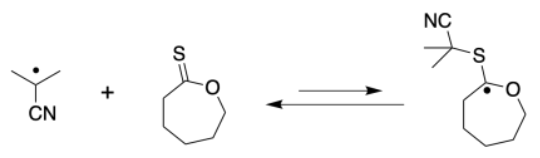

b)

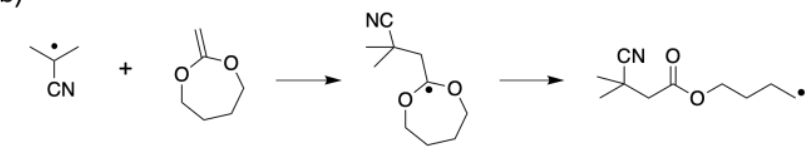

c)

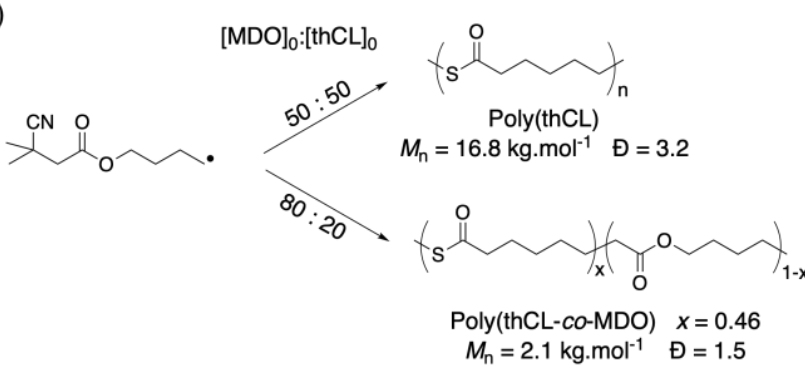

Scheme 2. Free-radical polymerization of thiono-caprolactone (thCL) and 2-methylene-1,3-dioxepane (MDO) performed in THF with AIBN initiation $(1 \mathrm{~mol} \%)$ and held at $70{ }^{\circ} \mathrm{C}$. a) Reversible trapping of AIBN in the presence of thCL thereby impeding the homopolymerization of thCL. b) Irreversible radical initiation during the copolymerization of thCL and MDO. c) (Co)polymers obtained depending of the initial feed ratio $[\mathrm{MDO}]_{0}:[\text { thCL }]_{0}$.

Preparation of P(VAc-co-thCL/thDL). The successful polymerization conditions to produce the homopolymer of thCL were performed in THF, but when analogous copolymerizations were attempted with vinyl acetate (VAc) they returned only minor quantities of polymer. Taking the minor quantities of polymer as a promising sign, a solvent change to ethyl acetate (EtOAc) was then performed due to its structural similarity with vinyl acetate. ${ }^{23}$ Such polymerizations readily produced copolymers of poly(thCL-co-VAc) and therefore a variety of polymerizations with differing feed ratios were then performed (Table 1). We showed that at higher feed ratios of the thCL monomer $(\geq 10 \%)$ the amount of thCL linkages within the polymer became enriched. Feed ratios above $20 \%$ thCL monomer failed to provide polymer, presumably because the thCL monomer was sequestering the AIBN derived radicals and thereby inhibiting the polymerization.

We thus tried to replace thiono-caprolactone (thCL) with thiono-decalactone (thDL) which would produce a secondary non-stabilized alkyl radical after ring-opening. It was hypothesized that this could enhance the ring-opening and also be more compatible with the low-stabilized secondary PVAc macroradical. The polymerization of a thDL: $\mathrm{VAc}=10: 90$ ratio led to poly(thDL-co-VAc $\mathrm{VA}_{4}$ ), showing a similar amount of thioester units $(20-22 \%)$ in the polymer backbone and thus still a higher amount of thioester in the polymer than in the feed. The ${ }^{1} \mathrm{H}$ NMR spectrum of the copolymerization between thCL and VAc and thDL and VAc is presented in Figure 2. Destarac and coworkers ${ }^{18}$ performed NMR analyses of the thCL/VAc copolymerization system and concluded that a large amount of the thCL is inserted as the cyclic ("closed") structure, analogous to the vinyl propagation of CKA monomers. Nevertheless, they specified that the cyclic structure was not concentrated enough to give definitive attributions.

Table 1. Free-radical polymerization of $\varepsilon$-thionocaprolactone $($ thCL)/ $\varepsilon$-thionodecalactone (thDL) and vinyl acetate (VAc) performed in EtOAc with AIBN initiation (1 mol\%) and held at $70{ }^{\circ} \mathrm{C}$. ${ }^{\text {a }}$ Calculated using ${ }^{1} \mathrm{H}$ NMR; ${ }^{b}$ Data measured using SEC (THF) with PS standards for calibration.

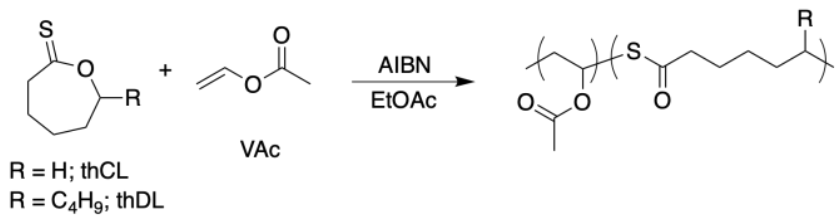

\begin{tabular}{|c|c|c|c|c|c|}
\hline $\begin{array}{c}\text { Feed ratio } \\
\text { thCL/thD } \\
\mathrm{L}(\%)\end{array}$ & $\begin{array}{c}\text { Feed } \\
\text { ratio } \\
\text { VAc } \\
(\%)\end{array}$ & Product $^{\mathrm{a}}$ & $\begin{array}{c}\% \\
\text { thCL/th } \\
\mathrm{DL}^{\mathrm{a}}\end{array}$ & $\begin{array}{c}M_{\mathrm{n}} \\
(\mathrm{kDa}) \\
\mathrm{b}\end{array}$ & $\begin{array}{c}\text { PDI } \\
\mathrm{b}\end{array}$ \\
\hline thCL (0) & 100 & poly(VAc) & - & 16.3 & 1.7 \\
\hline thCL (5) & 95 & $\begin{array}{c}\text { poly(thCL- } \\
\text { co-VAc }\end{array}$ & $3.6 \%$ & 17.0 & 2.3 \\
\hline thCL (10) & 90 & $\begin{array}{c}\text { poly(thCL- } \\
\text { co-VAc }\end{array}$ & $22.4 \%$ & 15.4 & 1.9 \\
\hline thDL (10) & 90 & $\left.\begin{array}{c}\text { Poly(thDL- } \\
\text { co-VAc }\end{array}\right)$ & $20.0 \%$ & 16.6 & 1.8 \\
\hline thCL (20) & 80 & $\begin{array}{c}\text { poly(thCL- } \\
\text { co-VAc }\end{array}$ & $58.1 \%$ & 8.5 & 1.9 \\
\hline thCL (50) & 50 & - & - & - & - \\
\hline
\end{tabular}

The ${ }^{1} \mathrm{H}$ NMR of the copolymer poly(thCL-co-VAc) samples displayed signals relating to the protons adjacent to the 
thioester, and from these protons the ratio of the monomers can be calculated (see ESI for details). The average of these two signals was used within calculations as they are not equal due to minor diad phenomena within the polymer chain. Interestingly, we did not observe large amounts of signals occurring between $3.2-4.15$ ppm that were ascribed to the "closed" structure. ${ }^{18}$ The ${ }^{1} \mathrm{H}$ NMR analysis of PVAc obtained using similar polymerization conditions presented a peak at $4.1 \mathrm{ppm}$ that could arise from chain branching or transfer to solvent, which is known to occur during the radical polymerization of VAc. $^{24,25}$ Moreover, the non-stabilized alkyl macroradical that is produced after the fragmentation of the thCL is prone to intra/intermolecular H-transfer. Such a feature has been widely documented in the case of MDO polymerization where 1,4 and 1,7 $\mathrm{H}$-intramolecular transfers and intermolecular $\mathrm{H}$-transfer were demonstrated, ${ }^{26}$ and whose amount increased exponentially with monomer conversion. ${ }^{20}$ The branching occurring via these processes could also be responsible for the signals at $3.2-3.8 \mathrm{ppm}$. In our case and contrary to the experiments done elsewhere, ${ }^{18}$ the copolymerization were performed in solution and thus the occurrence of H-transfer to the polymer was reduced. This could explain the very low amount of residual signal at $3.15-4.2 \mathrm{ppm}$. The copolymerization of thDL with VAc was also analyzed by ${ }^{1} \mathrm{H}$ NMR and presented a signal at $3.5 \mathrm{ppm}$ that is related to the methine group bearing the pendant butyl alkyl group. This NMR shift is in agreement with the hypothesis of $\mathrm{H}$-transfer occurring in the case of thCL. The presence of the $n$-butyl group could impede some intra/intermolecular H-transfers and lower the total amount of $\mathrm{H}$-transfer. A small signal (3-5\%) is still present at $3.2 \mathrm{ppm}$ that could be ascribed to $1,4 \mathrm{H}$-transfer.

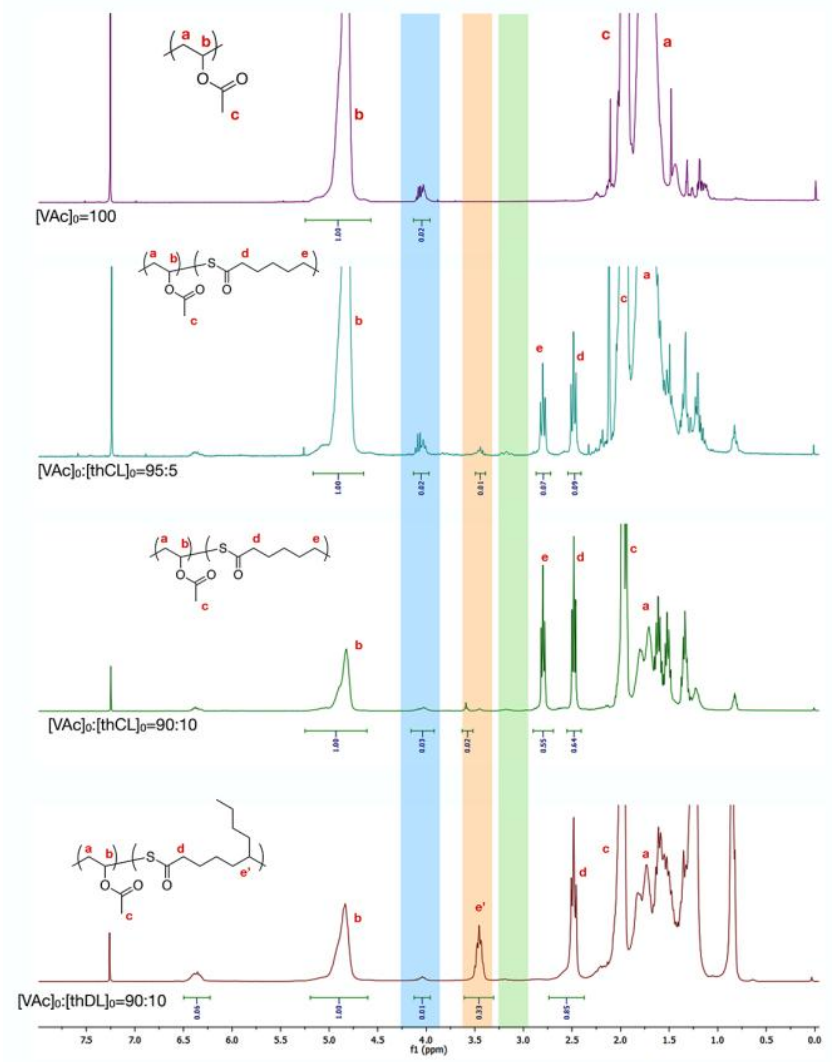

Figure 2. ${ }^{1} \mathrm{H}$ NMR analysis of the reference polyVAc (Table 1, Entry 1), poly(thCL-co-VAc 26.7 ) (Table 1, Entry 2), poly(thCL-
co-VAc ${ }_{3.5}$ ) (Table 1, Entry 3) and the poly(thDL-co-VAC 4 ) (Table 1, Entry 4).

Degradation studies. The degradation was then studied by aminolysis such as previously reported. ${ }^{11,} 12$ Poly(thCL-co$\mathrm{VAc}_{26.7}$ ) (Table 1, Entry 2) was thereby treated in THF by the addition of $N$-isopropylamine. It should be noted that the SEC trace before degradation is not completely symmetrical owing to chain-transfer during the polymerization of VAc. ${ }^{27}$ After degradation, the molecular weight $\left(M_{\mathrm{n}}\right)$ of the polymer was observed to change from 17,000 to $6,800 \mathrm{~g} / \mathrm{mol}$ (Figure 3). The decrease in the $M_{\mathrm{n}}$ (three-fold) is lower than expected (67 -fold according to $3.6 \mathrm{~mol} \%$ of thioester linkages) since the higher reactivity of thCL compared to VAc lead to diads or longer sequences of thioester units in the backbone. This result thereby confirmed only a relative homogeneous incorporation of the thCL linkages within the PVAc backbone, even if the whole distribution is shifted towards lower masses. As expected, the increase of the thCL ratio into the PVAc backbone led to an enhanced degradation (Figure $3, M_{\mathrm{n}}$ decrease from 15,400 to $1,700 \mathrm{~g} \cdot \mathrm{mol}^{-1}$ ). Compared to the radical copolymerization of CKA and vinyl acetate which also leads to degradable materials via hydrolysis, ${ }^{28,}{ }^{29}$ thCL allows the use of aminolysis as demonstrated in this work, while both transthioesterification $^{30}$ and oxidative hydrolysis ${ }^{30}$ should also be able to be applied as stimuli for degradation.

Destarac and coworkers ${ }^{18}$ showed that vinyl pivalate could be efficiently copolymerized with thCL. In a similar way, we were interested to extend the scope of vinyl acetate derivatives that could be copolymerized with thCL or thDL. Polyvinyl acetate is widely used as a precursor for the preparation of polyvinyl alcohol. ${ }^{31}$ Dove and Gibson ${ }^{32}$ reported the preparation of degradable poly(vinyl alcohol) via the radical copolymerization of MDO and vinyl chloroacetate ( $\mathrm{VAcCl})$.

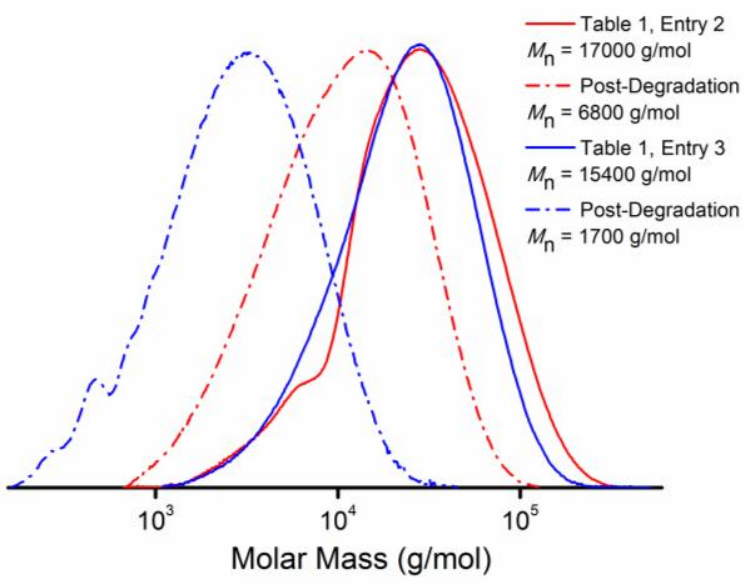

Figure 3. SEC traces of poly(thCL-co-VAc 26.7 ) (Table 1, Entry 2) and poly(thCL-co-VAc $\mathrm{VA}_{3.5}$ ) (Table 1, Entry 3) before and after degradation by aminolysis using $N$-isopropylamine.

Indeed, it is reported that chloroacetate esters have a hydrolysis rate 700 times higher than unmodified acetate esters, allowing the hydrolysis of the pendant group without the degradation of the ester in the main chain. ${ }^{33} \mathrm{We}$ thus try to copolymerize vinyl chloroacetate $(\mathrm{VAcCl})$ and thCL to prepare (bio)degradable polyvinyl alcohol. Unfortunately, copolymerizations of thCL and $\mathrm{VAcCl}$ were found to be unsuccessful. Tercopolymerizations between thCL, VAc and VAcCl (10:45:45) were also found to be unsuccessful. Such 
results are rather surprising since the macroradical that is produced after the ring-opening of the thCL is similar to the one that is produced after the ring-opening of the MDO. One explanation to the absence of polymer could be that reversible addition on the $\mathrm{C}=\mathrm{S}$ bond led to an increase in the lifetime of the growing poly(thCL) macroradical which is prone to abstract the chlorine atom of the $\mathrm{VAcCl}$. This was indeed another indirect proof that extensive $\mathrm{H}$-transfer occurred when thCL was polymerized. To decrease the ability to undergo transfer reactions, we also replaced the thCL with thDL to obtain a secondary alkyl radical instead of a primary radical. The copolymerization between thDL and $\mathrm{VAcCl}$ was then performed but was also found to not lead to the desired copolymer. This result showed that the ester moiety of the vinyl ester derivatives has to be carefully chosen when copolymerizing with thionolactone derivatives.

It has been reported that polyvinyl acetate can be stoichiometrically hydrolyzed to polyvinyl alcohol (PVOH) when the hydrolysis is performed in a mixture of acetone/ $\mathrm{H}_{2} \mathrm{O}$ using calculated quantities of $\mathrm{NaOH} .{ }^{34}$ Using this protocol, attempts were therefore made at the selective hydrolysis of the acetate groups within the poly(thCL-co-VAc) copolymer to provide (bio)degradable copolymers of polyvinyl alcohol, i.e. poly(thCL-co-VOH). Unfortunately, it was found that the hydrolysis reaction affected both esters and thioesters at equal rates. A variety of conditions were attempted, including targeting different quantities of hydrolysis (i.e., 20\%, 88\%) but without success.

Block copolymerizations using thCL. To extend the scope of the copolymerization between thCL and VAc, we then explored their RAFT polymerization in order to control the length and the dispersity of the copolymer. We performed the RAFT copolymerization using xanthates ${ }^{35}$ and dithiocarbamates $^{36}$ as RAFT agents. Rhodixan A1 (Figure 4) has been previously shown to be very efficient in controlling the polymerization of less activated monomers, especially vinyl acetate. ${ }^{37}$ Interestingly it was found that RAFT copolymerizations employing Rhodixan A1 failed when using a ratio $[\mathrm{RAFT} \text { Agent }]_{0} /[\mathrm{AIBN}]_{0}=10$, but gave a relatively well-controlled polymerization when a ratio of 3 was used. This is presumably due to the reversible addition phenomenon described above, thereby sequestering the free-radical initiator species and preventing propagation. The polymerizations were performed using a thCL:VAc ratio of 10:90 and thus led to a relatively well-defined polyvinyl acetate $\left(M_{\mathrm{n}}=4,200 \mathrm{~g} \cdot \mathrm{mol}^{-1}\right.$, $Ð=1.5)$ containing $26.7 \%$ thioester units. These results are in good agreement with recent study of Destarac and coworkers. ${ }^{18}$ At such ratios, non-stabilized alkyl moieties could be the dominant RAFT end-group, explaining the only moderate control of the polymerization. D'Agosto and coworkers $^{38}$ recently reported that dithiocarbamate RAFT agents were particularly efficient for the control of polymerizations involving ethylene, whose end-group is similar to the thioester moiety. We thus tried a dithiocarbamate RAFT agent, (i.e. the cyanomethyl methyl(phenyl)carbamodithioate) with a $[\text { RAFT Agent }]_{0} /[\mathrm{AIBN}]_{0}=3$ but the polymerization was not successful.
To further showcase the usefulness of this thionolactone monomer, block (co)polymerizations were then also investigated. We focused on the preparation of an amphiphilic block copolymer consisting on a hydrophilic block of $N, N$ dimethylacrylamide (DMAA) and a hydrophobic block of vinyl acetate. With this combination of monomer, it is possible to insert thioester linkages via the DOT monomer into the DMAA backbone, ${ }^{30}$ and thCL into the vinyl acetate backbone to degrade selectively one or two blocks of the copolymer.

To do this, a homopolymer of $N, N$-dimethylacrylamide was prepared using Rhodixan A1 as a RAFT agent. ${ }^{39}$ A copolymer of DMAA and DOT was then also prepared in an analogous manner (Figure 4). Using the isolated polymer samples as RAFT macroinitiators, a second (co)polymerization was then performed using VAc, or a mixture of VAc and thCL, to give three dissimilar block copolymers (Figure 4). These block copolymers were then degraded by aminolysis and their molecular weights examined by SEC. As expected, the first copolymer without any thioester units poly(DMAA)- $b$-(VAc) did not undergo any degradation via aminolysis. The incorporation of thioester linkages via the copolymerization of VAc and thCL was then performed using a VAc:thCL 95:5 ratio. The degradation via aminolysis using $N$-isopropylamine in THF showed the degradation of the second block even if there was some residual VAc units that could remain linked to the PDMMA end-group. The last copolymer was designed to insert thioester units both into the hydrophilic and hydrophobic cores via the use of DOT and thCL, respectively. The degradation was then performed via aminolysis using ammonia in methanol since this method was reported to be more effective for the degradation of DMAA-DOT copolymers by Roth and coworkers. ${ }^{30}$ The analysis by SEC of the degradation confirmed the degradation of both the hydrophilic and hydrophobic segments thereby showing the effectiveness of thionolactone technology to prepare degradable polymers (Figure 4).

\section{CONCLUSION}

In this article we reported the synthesis and rROP polymerization of two thionolactone monomers, i.e oxepane-2-thione (thiono-caprolactone, thCL) and 7-butyloxepane-2-thione (thiono-decalactone, thDL).Samples of homopolymer, as well as copolymers of thCL/thDL and vinyl acetate were prepared by free-radical polymerization and controlled RAFT polymerization. It was demonstrated that these monomers polymerize to provide thioester linkages within the polymer backbone which are readily degradable by aminolysis, thereby allowing the preparation of (bio)degradable poly(vinyl acetate) copolymers. Additionally, the preparation of a variety of block copolymers consisting of DMAA and vinyl acetate monomers with thioester units inside either one or two blocks is reported, their subsequent degradation being performed and examined by SEC to further demonstrate the usefulness of the reported monomer. 

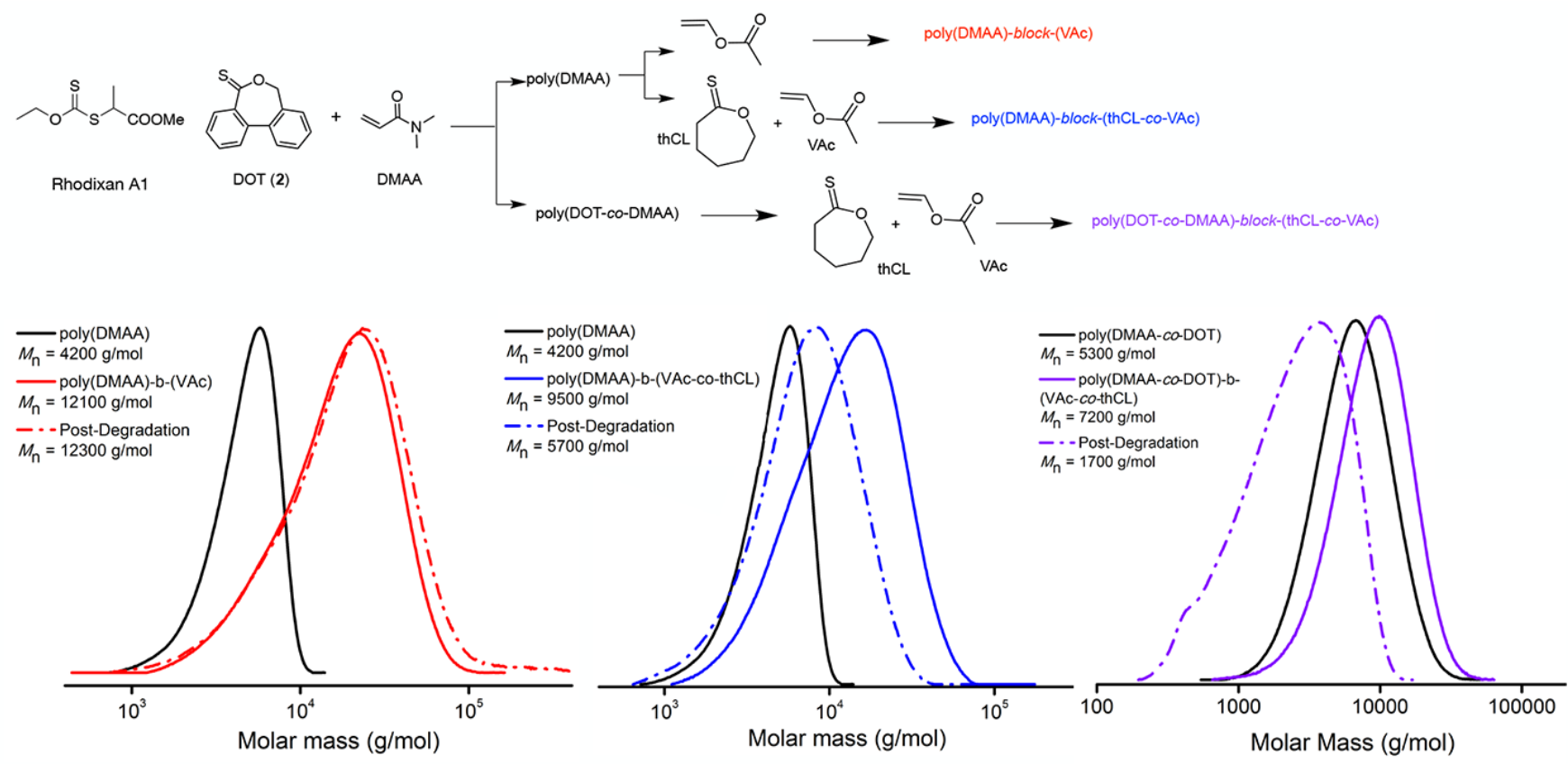

Figure 4. Preparation of block copolymers containing both $N, N$-dimethylacrylamide and vinyl acetate using both DOT and thCL to insert thioester

units.

\section{ASSOCIATED CONTENT}

\section{Supporting Information}

The Supporting Information is available free of charge on the ACS Publications website.

Synthesis of the thionolactone monomers; ${ }^{1} \mathrm{H}$ NMR spectra and SEC chromatograms of the (co)polymers (PDF).

\section{AUTHOR INFORMATION}

\section{Corresponding Author}

* Dr. Yohann Guillaneuf, Email: yohann.guillaneuf@univ-amu.fr

\section{Author Contributions}

The manuscript was written through contributions of all authors.

\section{Funding Sources}

This work was supported by Solvay Novecare. We thank the French National Research Agency (ANR-18-CE08-0019) for PhD funding $(\mathrm{NG})$.

\section{ACKNOWLDGMENT}

We thank the CNRS and Aix-Marseille University for support.

\section{REFERENCES}

1. Miller, S. A., Sustainable Polymers: Opportunities for the Next Decade. ACS Macro Lett. 2013, 2 (6), 550-554.

2. Napper, I. E.; Thompson, R. C., Environmental Deterioration of Biodegradable, Oxo-biodegradable, Compostable, and Conventional Plastic Carrier Bags in the Sea, Soil, and Open-Air Over a 3-Year Period. Environ. Sci. Technol. 2019, 53 (9), 47754783 .

3. de Souza Machado, A. A.; Kloas, W.; Zarfl, C.; Hempel, S.; Rillig, M. C., Microplastics as an emerging threat to terrestrial ecosystems. Global Change Biology 2018, 24 (4), 1405-1416.

4. Agarwal, S., Chemistry, chances and limitations of the radical ring-opening polymerization of cyclic ketene acetals for the synthesis of degradable polyesters. Polymer Chemistry 2010, 1 (7), 953-964.

5. Tardy, A.; Nicolas, J.; Gigmes, D.; Lefay, C.; Guillaneuf, Y., Radical Ring-Opening Polymerization: Scope, Limitations, and Application to (Bio)Degradable Materials. Chemical Reviews 2017, 117 (3), 1319-1406.

6. Pesenti, T.; Nicolas, J., 100th Anniversary of Macromolecular Science Viewpoint: Degradable Polymers from Radical Ring-Opening Polymerization: Latest Advances, New Directions, and Ongoing Challenges. Acs Macro Letters 2020, 9 (12), 1812-1835.

7. Gigmes, D.; Van Steenberge, P. H. M.; Siri, D.; D'Hooge, D. R.; Guillaneuf, Y.; Lefay, C., Simulation of the Degradation of Cyclic Ketene Acetal and Vinyl-Based Copolymers Synthesized via a Radical Process: Influence of the Reactivity Ratios on the Degradability Properties. Macromolecular Rapid Communications 2018, 39 (19), 1800193.

8. Tardy, A.; Gil, N.; Plummer, C. M.; Zhu, C.; Harrisson, S.; Siri, D.; Nicolas, J.; Gigmes, D.; Guillaneuf, Y.; Lefay, C., DFT-calculation-assisted prediction of the copolymerization between cyclic ketene acetals and traditional vinyl monomers. Polymer Chemistry 2020, 11 (45), 7159-7169.

9. Paulusse, J. M. J.; Amir, R. J.; Evans, R. A.; Hawker, C. J., Free Radical Polymers with Tunable and Selective Bio- and Chemical Degradability. Journal of the American Chemical Society 2009, 131 (28), 9805-9812.

10. Huang, H. C.; Sun, B. H.; Huang, Y. Z.; Niu, J., Radical Cascade-Triggered Controlled Ring-Opening Polymerization of Macrocyclic Monomers. Journal of the American Chemical Society 2018, 140 (33), 10402-10406.

11. Bingham, N. M.; Roth, P. J., Degradable vinyl copolymers through thiocarbonyl addition-ring-opening (TARO) polymerization. Chemical Communications 2019, 55 (1), 55-58.

12. Smith, R. A.; Fu, G.; McAteer, O.; Xu, M.; Gutekunst, W. R., Radical Approach to Thioester-Containing Polymers. Journal of the American Chemical Society 2019, 141 (4), 1446-1451.

13. Spick, M. P.; Bingham, N. M.; Li, Y. M.; De Jesus, J.; Costa, C.; Bailey, M. J.; Roth, P. J., Fully Degradable ThioesterFunctional Homo- and Alternating Copolymers Prepared through Thiocarbonyl Addition-Ring-Opening RAFT Radical Polymerization. Macromolecules 2020, 53 (2), 539-547. 
14. Moad, G.; Rizzardo, E.; Thang, S. H., Living radical polymerization by the RAFT process - A first update. Australian Journal of Chemistry 2006, 59 (10), 669-692.

15. Moad, G.; Rizzardo, E.; Thang, S. H., Living Radical Polymerization by the RAFT Process - A Second Update. Australian Journal of Chemistry 2009, 62 (11), 1402-1472.

16. Chiefari, J.; Mayadunne, R. T. A.; Moad, C. L.; Moad, G.; Rizzardo, E.; Postma, A.; Skidmore, M. A.; Thang, S. H., Thiocarbonylthio compounds $(\mathrm{S}=\mathrm{C}(\mathrm{Z}) \mathrm{S}-\mathrm{R})$ in free radical polymerization with reversible addition-fragmentation chain transfer (RAFT polymerization). Effect of the activating group $\mathrm{Z}$. Macromolecules 2003, 36 (7), 2273-2283.

17. Coote, M. L.; Henry, D. J., Effect of substituents on radical stability in reversible addition fragmentation chain transfer polymerization: An ab initio study. Macromolecules 2005, 38 (4), $1415-1433$.

18. Ivanchenko, O.; Authesserre, U.; Coste, G.; Mazieres, S.; Destarac, M.; Harrisson, S., epsilon-Thionocaprolactone: an accessible monomer for preparation of degradable poly(vinyl esters) by radical ring-opening polymerization. Polymer Chemistry 2021, 12 (13), 1931-1938

19. Curphey, T. J., Thionation with the reagent combination of phosphorus pentasulfide and hexamethyldisiloxane. Journal of Organic Chemistry 2002, 67 (18), 6461-6473.

20. Tardy, A.; Honore, J. C.; Siri, D.; Nicolas, J.; Gigmes, D.; Lefay, C.; Guillaneuf, Y., A comprehensive kinetic study of the conventional free-radical polymerization of seven-membered cyclic ketene acetals. Polymer Chemistry 2017, 8 (34), 5139-5147.

21. Wolpers, A.; Baffie, F.; Verrieux, L.; Perrin, L.; Monteil, V.; D'Agosto, F., Iodine-Transfer Polymerization (ITP) of Ethylene and Copolymerization with Vinyl Acetate. Angew Chem Int Ed Engl 2020, 59 (43), 19304-19310.

22. Moad, G.; Solomon, D. H., THE CHEMISTRY OF RADICAL POLYMERIZATION, SECOND FULLY REVISED EDITION. Elsevier Science: 2006.

23. Kermagoret, A.; Wenn, B.; Debuigne, A.; Jerome, C.; Junkers, T.; Detrembleur, C., Improved photo-induced cobaltmediated radical polymerization in continuous flow photoreactors. Polym. Chem. 2015, 6, 3847-3857.

24. Britton, D.; Heatley, F.; Lovell, P. A., Chain transfer to polymer in free-radical bulk and emulsion polymerization of vinyl acetate studied by NMR spectroscopy. Macromolecules 1998, 31 (9), 2828-2837.

25. De Rybel, N.; Van Steenberge, P. H. M.; Reyniers, M. F.; D'Hooge, D. R.; Marin, G. B., Interplay of Head, Tail, and Mid-Chain Radicals in Bulk Free-Radical and Reversible Degenerative Addition Fragmentation Chain Transfer Polymerizations of Vinyl Acetate. Macromolecules 2019, 52 (12), 4555-4569.

26. Jin, S.; Gonsalves, K. E., A Study of the Mechanism of the Free-Radical Ring-Opening Polymerization of 2-Methylene-1,3dioxepane. Macromolecules 1997, 30 (10), 3104-3106.

27. Grcev, S.; Schoenmakers, P.; Iedema, P., Determination of molecular weight and size distribution and branching characteristics of PVAc by means of size exclusion chromatography/multi- angle laser light scattering (SEC/MALLS). Polymer 2004, 45 (1), 39-48.
28. Agarwal, S.; Kumar, R.; Kissel, T.; Reul, R., Synthesis of Degradable Materials Based on Caprolactone and Vinyl Acetate Units Using Radical Chemistry. Polymer Journal 2009, 41 (8), 650-660.

29. d'Ayala, G. G.; Malinconico, M.; Laurienzo, P.; Tardy, A.; Guillaneuf, Y.; Lansalot, M.; D'Agosto, F.; Charleux, B., RAFT/MADIX Copolymerization of Vinyl Acetate and 5,6-Benzo-2methylene-1,3-dioxepane. Journal of Polymer Science Part aPolymer Chemistry 2014, 52 (1), 104-111.

30. Bingham, N. M.; Nisa, Q. U.; Chua, S. H. L.; Fontugne, L.; Spick, M. P.; Roth, P. J., Thioester-Functional Polyacrylamides: Rapid Selective Backbone Degradation Triggers Solubility Switch Based on Aqueous Lower Critical Solution Temperature/Upper Critical Solution Temperature. Acs Applied Polymer Materials 2020, 2 (8), 3440-3449.

31. Fabini, M.; Bobula, S.; Rusina, M.; Macho, V.; Harustiak, M., PREPARATION OF POLY(VINYL ALCOHOL) AS THE DISPERSANT FOR SUSPENSION VINYL-CHLORIDE POLYMERIZATIONS. Polymer 1994, 35 (10), 2201-2204.

32. Hedir, G.; Stubbs, C.; Aston, P.; Dove, A. P.; Gibson, M. I., Synthesis of Degradable Poly(vinyl alcohol) by Radical RingOpening Copolymerization and Ice Recrystallization Inhibition Activity. ACS Macro Lett. 2017, 6, 1404-1408.

33. Olijve, L. L. C.; Hendrix, M. M. R.; Voets, I. K., Influence of Polymer Chain Architecture of Poly(vinyl alcohol) on the Inhibition of Ice Recrystallization. Macromol. Chem. Phys. 2016, 217, 951-958.

34. Chana, J.; Forbes, B.; Jones, S. A., The Synthesis of High Molecular Weight Partially Hydrolysed Poly(vinyl alcohol) Grades Suitable for Nanoparticle Fabrication J. Nanosci. Nanotechnol. 2008, 5739-5747.

35. Stenzel, M. H.; Cummins, L.; Roberts, G. E.; Davis, T. P.; Vana, P.; Barner-Kowollik, C., Xanthate mediated living polymerization of vinyl acetate: A systematic variation in MADIX/RAFT agent structure. Macromolecular Chemistry and Physics 2003, 204 (9), 1160-1168.

36. Moad, G., A Critical Survey of Dithiocarbamate Reversible Addition-Fragmentation Chain Transfer (RAFT) Agents in Radical Polymerization. Journal of Polymer Science Part a-Polymer Chemistry 2019, 57 (3), 216-227.

37. Harrisson, S.; Liu, X.; Ollagnier, J. N.; Coutelier, O.; Marty, J. D.; Destarac, M., RAFT Polymerization of Vinyl Esters: Synthesis and Applications. Polymers 2014, 6 (5), 1437-1488.

38. Wolpers, A.; Bergerbit, C.; Ebeling, B.; D'Agosto, F.; Monteil, V., Aromatic Xanthates and Dithiocarbamates for the Polymerization of Ethylene through Reversible AdditionFragmentation Chain Transfer (RAFT). Angewandte ChemieInternational Edition 2019, 58 (40), 14295-14302.

39. Vakili, M.; Cunningham, V. J.; Trebbin, M.; Theato, P., Polymerization-Induced Thermal Self-Assembly of Functional and Thermo-Responsive Diblock Copolymer Nano-Objects via RAFT Aqueous Polymerization. Macromolecular Chemistry and Physics 2019, 220 (2), 1800370. 


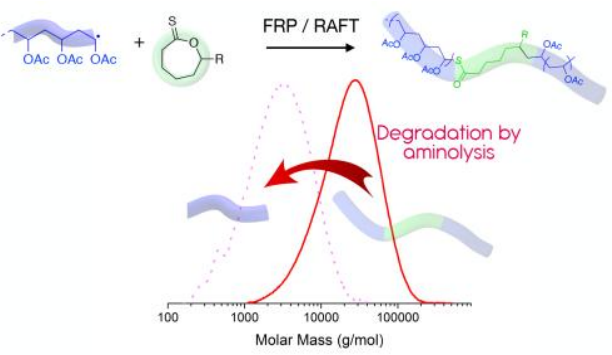

